\section{A pressurized liquid reinforcement delivery system}

\section{JOSEPH M. HARRISON and STEPHEN W. SEXAUER Life Sciences Division, Technology Incorporated 511 West Rhapsody, San Antonio, Texas 78216}

Liquid reinforcement is commonly used in training monkeys to perform visual observing tasks (Crawford, 1976; Harwerth \& Sperling, 1975; Poggio, Doty, \& Talbot, 1977; Wurtz, 1969). The task in these experiments is to hold down a spring-loaded lever while observing a small, dim fixation light during the observa. tion period, to release the lever at the offset of the light, and not to press the lever during the short intertrial interval between observation periods. Liquid reinforcement is delivered by a gravity-fed device through a solenoid valve.

Our experience with the gravity-fed liquid solenoid valve in a visual observation task showed that water reinforcement delivery was temporally dispersed throughout the intertrial interval and the succeeding observation period. An open reservoir below the solenoid valve did not solve this problem. The monkeys (Macaca mulatta) missed quantities of water because of the variability of the arrival time of the droplets. Thus, it was difficult to measure accurately the amount of water consumed. In addition, the monkeys repetitively mouthed and licked the drink spout and were able to shake loose droplets adhering to the inner walls of the connecting tube.

The variability of arrival time of reinforcement and the advantage derived from mouthing and licking the drink spout combined to produce a set of behaviors competing with the observation task.

The apparatus described in this report was designed to deliver a discrete spurt of liquid reinforcement with low variability of volume and arrival time. A commercially available liquid delivery system (BRS/LVE Model LSC-002) was modified to achieve this end. Figure 1 is a diagram of the apparatus.

The closed water reservoir is kept pressurized at $.6 \mathrm{~kg} / \mathrm{cm}^{2}$. The solenoid valve is connected to the reservoir output tube. When the valve opens, a pressurized stream of water flows into the tube connecting the drink spout and the valve. The tube and the spout are filled with water before the session so that a spurt of water is projected from the drink spout in an arch $2 \mathrm{~cm}$ to the monkey's mouth. The distance separating

This research was supported by Contract F33615-77-C0615, USAF School of Aerospace Medicine, Aerospace Medical Division, Air Force Systems Command. Work was performed in the Laser Effects Branch, USAF School of Aerospace Medicine, Brooks AFB, Texas. Reprints may be obtained from Joseph M. Harrison, Technology Incorporated, Life Sciences Division, 511 West Rhapsody, San Antonio, Texas 78216.

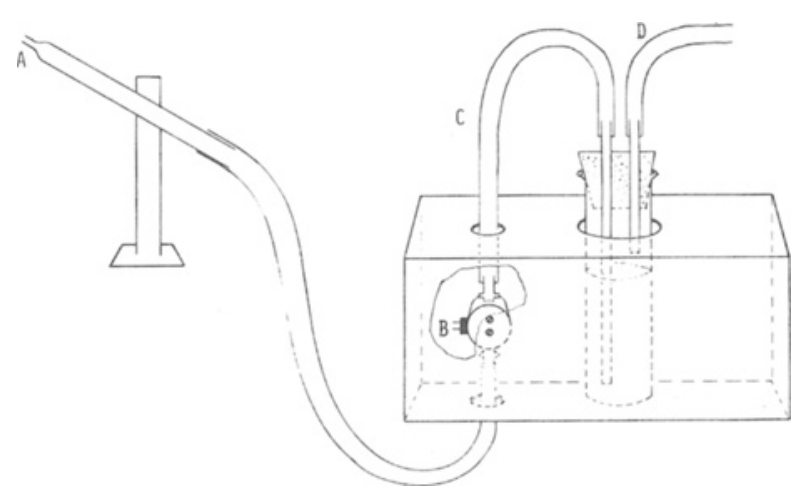

Figure 1. Diagram of the pressurized liquid delivery system. Polyethylene connecting tubing length is adjustable within wide limits. (A) Drink spout, (B) leads from programming equipment to the solenoid valve, (C) output tube, (D) input tube connects to the pressurizer.

the monkey's mouth and the drink spout prevents licking and mouthing.

The monkeys that were trained using this system rapidly learned in one session to catch the water in mid-air. The system in use delivered a mean of $.71 \mathrm{ml}$ of water per trial, with a standard error of the mean of .02 over 14 trials. All of the water delivered was consumed. There was never any indication of water spillage around the monkey.

Training of two monkeys in the visual observation task using this method of reinforcement delivery proceeded rapidly. A total of 46 sessions from the first shaping session was required to achieve $85 \%$ correct responses (reaction time $\leqslant 600 \mathrm{msec}$ ) with a red lightemitting-diode fixation light source subtending $3.4 \times 5.1 \mathrm{~min}$ of arc visual angle at the monkey's eye and set at a luminance of $4.8 \mathrm{~cd} / \mathrm{m}^{2}$.

Another advantage of this type of reinforcement became evident when electrophysiological recordings were made during the observation period. Eliminating mouthing and licking minimized high-voltage movementassociated artifacts that obscured the visual evoked responses.

\section{REFERENCES}

Crawford, M. L. J. Behavioral control of visual fixation of the Rhesus monkey. Journal of the Experimental Analysis of Behavior, 1976, 25, 113-121.

Harwerth, R. S., \& Sperling, H. G. Effects of intense visible radiation on the increment threshold spectral sensitivity of the Rhesus monkey eye. Vision Research, 1975, 15, 1193-1204.

Poggio, G. F., Doty, R. W., \& Talbot, W. H. Foveal striate cortex of behaving monkey: Single-neuron responses to square wave gratings during fixation of gaze. Journal of Neurophysiology, 1977, 40, 1369-1391.

WURTz, R. H. Visual receptive fields of striate cortex neurons in awake monkeys. Journal of Neurophysiology, 1969, 32, 727-742.

(Accepted for publication June 10, 1979.) 